\title{
A "IDEOLOGIA DE GÊNERO"E A “ESCOLA SEM PARTIDO": FACES DE UMA MESMA MOEDA EM AÇÕES POLÍTICAS CONSERVADORAS NO BRASIL E NO ESPÍRITO SANTO
}

\author{
ERINeUSA Maria da SILVA \\ Universidade Federal do Espírito Santo (UFES), Vitória, Espírito Santo, \\ Brasil \\ Elda Alvarenga \\ FÁbio LuIz Alves de AmOrIM \\ Faculdade Estácio de Sá, Vila Velha, Espírito Santo, Brasil \\ ElizA BARTOLOZZI FerReIRA \\ Universidade Federal do Espírito Santo (UFES), Vitória, Espírito Santo, \\ Brasil
}

\begin{abstract}
Resumo: Este artigo tem como objetivo compreender as ações políticas atuais em torno das discussões sobre doutrinação, gênero e diversidade sexual, em especial as tocantes às propostas denominadas "ideologia de gênero" e "Escola sem partido", bem como as tensões e as implicações desse debate para a compreensão do papel da escola e dos/as professores/as frente à formação humana. Para atender aos objetivos, utiliza a pesquisa bibliográfica. Nesse percurso, problematiza sobre as intencionalidades político-religiosas que recaem sobre essas propostas, compreendendo-as como duas ações articuladas. Conclui que, atualmente, o Brasil passa por um processo de contenção aos avanços nas políticas e ações sociais conquistados nos últimos 15 anos e, simultaneamente, por um movimento de resistências que perpassa, necessariamente, pelos processos educativos e pela ação de professores/as.
\end{abstract}

Palavras-chave: Políticas Públicas. Atores sociais. Ideologia de gênero. Escola sem Partido. 


\section{INTRODUÇÃO}

Este artigo tem por objetivo contribuir para o debate sobre ações políticas atuais em torno das discussões sobre doutrinação, gênero e diversidade sexual nos currículos escolares. A análise desenvolvida é crítica aos projetos denominados "Ideologia de gênero" e "Escola sem partido"1, os quais se apresentam como duas propostas de ações político-religiosas articuladas e violam princípios básicos orientadores do trabalho escolar. Consideramos fundamental compreender as tensões e as implicações do debate a fim de fortalecer o papel da escola e dos/as professores/as na defesa de uma escola que prime pelo respeito às diferenças e pela necessidade de romper com desigualdades (re) produzidas internamente pela instituição escolar.

Este artigo consta de três sessões, além da introdução e das considerações finais. A primeira traz aspectos introdutórios para refletir sobre o contexto das políticas educacionais em que as diversidades e diferenças assumem seu protagonismo e provocam resistências por parte da elite política brasileira. A sessão seguinte descreve fatos que configuram o crescimento da onda conservadora no Brasil e no Espírito Santo, organizada na direção de reprimir o debate sobre gênero na escola. A terceira sessão trata especificamente do projeto da "Escola sem partido", a partir do argumento de que ambas as propostas fazem parte de uma mesma agenda conservadora.

\section{ENSAIOS DA DEMOCRACIA BRASILEIRA NO INÍCIO DO SÉCULO XXI}

Após a entrada do neoliberalismo na história do Brasil, no final do século XX, o que gerou mudanças profundas na organização social, política e econômica do país referenciadas pelas privatizações e novas formas conservadoras de ação social, o início do século XXI revelou uma guinada mais à esquerda no que tange ao trabalho do Estado na formulação de políticas sociais. Em 2003, com a eleição de um governo democráticopopular, muitos movimentos sociais tiveram espaço de diálogo e de conquistas, mesmo ainda pequenas em relação à gravidade dos problemas históricos do país. Não obstante a permanência da política econômica em caráter neoliberal, secretarias ${ }^{2}$ foram criadas com missões de implantar políticas para os segmentos minoritários do país, especialmente voltadas para as questões de gênero e étnico-raciais.

Conquistas aconteceram também no campo da educação. Para este texto, é importante destacar a organização da sociedade civil no interior das Conferências Nacionais de Educação (Conaes) as quais envolveram muitos participantes em todo o território nacional para o debate sobre os rumos da educação brasileira e construção do Plano Nacional de Educação (PNE). Especificamente sobre as questões de gênero e diversidade sexual, o documento final da Conae (MEC/CONAE, 2010, p. 143) defende, entre muitas ações, a necessidade de: 
SILVA, E.M.; ALVARENGA, E.; AMORIM, F.L.A.; FERREIRA, E.B.

Introduzir e garantir a discussão de gênero e diversidade sexual na política de valorização e formação inicial e continuada dos/das profissionais da educação nas esferas federal, estadual, distrital e municipal, visando ao combate do preconceito e da discriminação de pessoas lésbicas, gays, bissexuais, travestis, transexuais, mulheres, ao estudo de gênero, diversidade sexual e orientação sexual, no currículo do ensino superior, levando-se em conta o Plano Nacional de Políticas Públicas para a Cidadania LGBT e o Programa Brasil sem Homofobia.

Essa visibilidade das questões de gênero e da diversidade étnico-racial em um documento de tamanha importância marca a história da educação brasileira. Todavia, no texto final do PNE (Lei no 13.005/2016), foi ignorada qualquer menção à igualdade de gênero para formular políticas públicas em educação, sob o argumento de parlamentares de que essa discussão não deve ser objeto de reflexão da escola.

\section{IDEOLOGIA DE GÊNERO: CONCEITOS E AÇÕES EM DEBATE}

No Brasil, principalmente desde o início do século XXI, a práxis políticopedagógica da escola tem como marca a valorização de conteúdos e práticas curriculares que evidenciam o direito à diversidade e explicitam a naturalização de hierarquias e de desigualdades de classe, de raça/etnia e de gênero. As práticas pedagógicas se direcionam por um movimento de desnaturalização, portanto com base crítica dessas relações que têm sido legitimadas socialmente e também pela escola. Em sentido inverso, com força política crescente, alguns movimentos de resistência adquiriram espaços midiáticos e no Poder Legislativo. Essa resistência teve seu início na questão de gênero, com a denominada ideologia de gênero, ainda no ano de 2014, por ocasião da aprovação do Plano Nacional de Educação. Nessa esteira, em 2015, o "Escola sem partido" toma a cena política do país.

Assim, desde 2014, de forma mais nítida, pudemos observar a retomada das forças sociais conservadoras em torno do que elas chamam de "ideologia de gênero". Essas forças, expressas por alas conservadoras católicas e neopentencostais, por meio de seus líderes religiosos e líderes parlamentares representantes na Câmara e no Senado, afirmam estar ocorrendo "[...] uma conspiração internacional que quer 'perverter' as crianças, ensiná-las a ser gays e destruir a família dita tradicional" (REIS, 2015, p. 1) e que a ideologia de gênero, ao contrário de respeitar o "[...] pressuposto antropológico de uma visão integral do ser humano, fundamentada nos valores humanos e éticos, identidade histórica do povo brasileiro [...] vai no caminho oposto e desconstrói o conceito de família, que tem seu fundamento na união estável entre homem e mulher" (CNBB, 2015, p. 1).

No curso desse debate social, é exemplar a divulgação da Revista Comunhão ( $\mathrm{n}^{\circ}$ 215, de junho de 2015), cuja capa - Silas Malafaia: "batalha contra a ideologia de gênero" - apresenta a manchete da entrevista com o pastor presidente da Assembleia de Deus Vitória em $\mathrm{Cristo}^{3}$. Na entrevista, o pastor se coloca como uma das vozes dos evangélicos que defende a família tradicional e que luta para impedir que o Ministério da Educação insira no Plano Nacional de Educação a ideologia de gênero nas escolas que, segundo o 
pastor, "[...] determina a ausência de sexo desde o nascimento da criança até sua decisão sobre qual deles optará: feminino ou masculino" (MALAFAIA, 2015). Com ações de caráter religioso-parlamentar-midiático desse tipo por parte das Igrejas, observamos uma dificuldade relacionada especialmente com alguns grupos religiosos em aceitar ações de cunho pedagógico que envolvam os debates referentes aos temas gênero e diversidade sexual realizados pelas escolas por todo o Brasil.

Sob as alegações expostas, passamos a assistir, em nível nacional, ao ataque à denominada "ideologia de gênero", que, segundo os conservadores, está presente no Plano Nacional de Educação e nos Planos Estaduais e Municipais de Educação. Nesse processo, pudemos perceber que a ideia de uma educação que preconiza a igualdade de gênero e o respeito à diversidade defendidos pelos movimentos feministas e de mulheres, paulatinamente assumida pelas políticas públicas e sociais como uma ação afirmativa, foi apropriada por esses setores mais conservadores da sociedade. Assim, inverteram a sua lógica e, de forma perversa, passaram a concebê-las como políticas que preconizam uma denominada doutrinação de gênero.

Uma das investidas desse pensamento conservador afetou diretamente a educação quando, na votação do Plano Nacional de Educação, em 2014, o plenário da Câmara aprovou a retirada do termo gênero de todas as metas que se referiam à questão de gênero. Nessa linha de atuação e impondo-se em nível nacional, esse setor conseguiu "minar" uma parte importante dos instrumentos legais que orientam a política educacional do país, quais sejam, o Plano Nacional, os Estaduais e Municipais de Educação. Mas de onde surge esse movimento denominado "ideologia de gênero"?

Esse movimento de tensão em torno das questões de gênero parece se apresentar como um fenômeno internacional alavancado principalmente pelas alas conservadoras de neopentencostais e católicos. Na Itália, o foco foi o Family Day ocorrido na Praça de São João em Roma, quando pessoas portavam cartazes com slogans como: "Tirem as mãos dos nossos filhos", "Nascemos homem e mulher", "Parem o gênero nas escolas", "O gênero é o esterco do diabo". Tal situação provocou a filósofa italiana Michela Marzano, professora da Universidade de Paris V René Descartes, a escrever o artigo ${ }^{4}$ intitulado $A$ cruzada contra o gênero, o fantasma que agita os católicos, publicado no jornal La Repubblica, em 22 de junho de 2015.

Nesse artigo, Michele Marzano (2015) problematiza o medo que há hoje na sociedade, por parte dos/as fundamentalistas religiosos, quanto à questão da identidade de gênero e da homossexualidade. A autora propõe pensar, a partir de diversos teóricos (Money, Lévi-Strauss e Foucault), que o sexo remete às características genéticobiológicas e que gênero diz respeito ao complexo de regras subentendidas às relações entre homens e mulheres. Com isso, Michele Marzano (2015) continua sua análise discutindo os estereótipos da formação e dos papéis destinados a homens e mulheres, apontando para a não existência de uma única "ideologia de gênero", mas um conjunto heterogêneo de posições, umas mais radicais e outras menos. Alerta que todas levam em consideração a complexidade do real, de que existem muitos modos de ser e de se sentir homem e de se sentir mulher.

A autora finaliza chamando a atenção para o objetivo desse debate, pois entende que esse processo favorece o respeito a qualquer ser humano, mesmo que sua identidade ou orientação sexual sejam diferentes. Com isso, desafia a orientação conservadora católica, diante da manifestação descrita nos cartazes "Tirem as mãos dos nossos filhos", a pensar em tirar as mãos também dos que sofrem por causa de sua 
identidade de gênero e/ou de sua orientação sexual, nas quais não há nada de monstruoso. Essa posição conservadora se apresenta também no Espírito Santo, com a presença de manifestações por parte da Igreja Católica e de denominações neopentencostais, como veremos adiante.

\section{A EXPERIÊNCIA CONSERVADORA NO ESPÍRITO SANTO}

A experiência vivida no Espírito Santo apresenta relação com o movimento ocorrido na Itália, especificamente, com a presença de manifestações por parte da Igreja Católica, representada pelo arcebispo de Vitória, Dom Luiz Mancilha Vilela. No dia 19 de junho de 2015, a Arquidiocese de Vitória divulgou uma carta intitulada "Declaração de Dom Luiz Mancilha Vilela sobre a Ideologia de Gênero", na página de notícias do seu site $^{5}$, na qual Vilela afirma, dentre outras questões, que a inclusão da "ideologia de gênero" nos Planos Nacional e Estaduais de Educação "destrói a família".

Nessa carta, que teve, inclusive, repercussões nos jornais locais como "A Gazeta" ${ }^{10}$, o Arcebispo alega também que, nessa lógica, os professores e as professoras são proibidos de tratar as crianças como menino e menina. A essa manifestação pública de Dom Luiz se unem outros líderes de Igrejas Neopentencostais fazendo coro contra a "ideologia de gênero", estimulando, pela voz da lgreja, uma legitimidade social (BOURDIEU, 2005). Por outro lado, diversos outros atores sociais, como o Fórum LGBT do Espírito Santo, o Coletivo de Diversidade Sexual do Sindicato dos Trabalhadores em Educação Pública do Espírito Santo (Sindiupes), a Central Única dos Trabalhadores, repudiaram publicamente a carta de Dom Luiz e as ações conservadoras das Igrejas?

Com e por isso, as plenárias ocorridas na Assembléia Legislativa e nas Câmaras Municipais de Vereadores da Grande Vitória para a aprovação dos Planos Estadual e Municipais de Educação foram palco de grande debate em torno da questão, mas, apesar das resistências, em todas as sessões, as votações realizadas pelos deputados e vereadores apontaram para a retirada de qualquer alusão à política de igualdade de gênero nos Planos de Educação, como se verá a seguir.

Na Capital capixaba, mesmo com as inúmeras tentativas de diálogo de representantes sindicais, do Conselho Municipal de Educação de Vitória (COMEV) ${ }^{8}$ e da Secretaria Municipal de Educação com a Câmara Municipal ${ }^{9}$, a versão final do Plano Municipal de Educação foi aprovada desprovida de toda e qualquer menção a gênero e à diversidade sexual. Após a derrota da proposta apresentada pelo Conselho Municipal de Educação, que fazia constar em seu texto as questões de gênero e da diversidade sexual, a Secretaria Municipal de Educação promoveu uma reunião com diversos líderes religiosos e com a bancada religiosa (assim assumida) da Câmara, para explicitar quais eram os parâmetros de debate sobre essas temáticas nas escolas municipais de Vitória.

Nessa reunião, assessores/as dos/as vereadores/as presentes afirmaram que, por um lado, foi explicada a proposta da Secretaria de Educação de manutenção dos termos gênero e diversidade sexual no Plano Municipal e, por outro, o que a Câmara entendia como ideologia de gênero. No entanto, o Plano não foi alterado, ou seja, tornou-se omisso quanto às relações sociais de gênero e da diversidade sexual. Inclusive, citadas nos mesmos parágrafos que os temas de gênero e diversidade sexual, as questões étnico-raciais ${ }^{10}$ também foram excluídas. No município de Serra, Grande Vitória, os vereadores Carlos Augusto Lorenzoni (PP) e Jorge Luiz da Silva (SDD) 
chegaram a propor uma Lei Municipal (PL no 124/15) proibindo, no âmbito do município, em escolas públicas e particulares, "[...] a promoção da diversidade de gênero, disseminar materiais pedagógicos que promovam igualdade de gênero, orientação sexual e identidade de gênero" (SERRA, 2015, p. 1).

Semelhante ao ocorrido na Câmara Municipal de Vitória, em Cariacica, Vila Velha e Viana, e em grande maioria dos municípios capixabas ${ }^{11}$, excluiu-se dos textos dos planos municipais de educação qualquer alusão aos termos gênero e diversidade sexual. Dessa forma, podemos afirmar que, lamentavelmente, a difusão equivocada dos pressupostos de gênero e da diversidade sexual foi fundamental para essa violação explícita da autonomia dos sistemas municipais de educação e uma afronta ao papel social dos/as professores/as. Percebemos que essas iniciativas ressoam em muitos espaços e tempos e, como não poderia deixar de ser, resvalam-se nos processos educativos e no trabalho cotidiano de professores e professoras. Nesse sentido, recuperar a compreensão de que o campo de estudo de gênero faz a respeito da construção do termo como uma categoria de análise torna-se importante para desqualificar o que se denomina de "ideologia de gênero".

\section{GÊNERO: QUAL IDEOLOGIA NOS INTERESSA?}

A apropriação que fazemos de gênero alinha-se à enunciação proposta por Scott (1995). Para ela, a preocupação teórica com o gênero, como categoria analítica, só emergiu no final do século XX. O termo surgiu num momento de grande efervescência epistemológica e tomou a forma, em certos casos, da mudança de um paradigma científico para um paradigma literário entre os/as cientistas sociais. Gênero faz parte da tentativa empreendida pelas feministas contemporâneas de reivindicar um novo terreno para explicar as persistentes desigualdades entre homens e mulheres.

Scott (1995) afirma que o termo gênero começou a ser utilizado pelas feministas como uma maneira de se referir à organização social da relação entre os sexos. Sua aparição primeira deu-se com as feministas inglesas e norte-americanas, que desejavam enfatizar o caráter fundamentalmente social das distinções baseadas no sexo e o aspecto relacional das definições normativas da feminilidade. Para essas feministas, as mulheres e os homens eram definidos reciprocamente e não poderiam compreender qualquer um dos sexos por meio de um estudo completamente separado. Referências e pioneiras na promoção do debate em torno do gênero no Brasil, Faria e Nobre (1997) enfatizam a necessidade de se compreender o conceito de "gênero" para a desconstrução das desigualdades entre os sexos. Para elas,

O conceito de gênero procura explicar as relações entre homens e mulheres; ele surgiu após muitos anos de luta feminista e de formulação de várias tentativas de explicações teóricas sobre a opressão das mulheres [...]. Esse conceito coloca claramente o ser mulher e ser homem como uma construção social a partir do que é estabelecido como masculino e feminino e dos papéis sociais destinados a cada um. Por isso gênero é um termo emprestado da gramática, foi a palavra escolhida para expressar a construção social do masculino e feminino (FARIA; NOBRE, 1997, p. 29-30).

As autoras apontam ainda a diferença entre gênero e sexo biológico. Para elas, “[...] sexo é a marca bio-anátomo-fisiológica, a caracterização genital e natural, 
constituída a partir da aquisição evolutiva da espécie humana como animal" (FARIA; NOBRE, 1997, p. 32). Por outro lado, gênero aparece como uma categoria de análise que coloca o homem e a mulher como seres relacionais e não em oposição binária. Gênero é visto como um "[...] conceito relacional, ou seja, que vê um em relação ao outro" (p. 32) e busca superar o caráter binário da análise das relações entre homens e mulheres. Gênero parte do pressuposto de que as relações estabelecidas entre os sexos são relações de poder e de hierarquização dos homens sobre as mulheres. Nesse sentido, o conceito pretende referir-se ao modo como as características sexuais são compreendidas e representadas socialmente.

Semelhante ao que fez Joan Scott, Judith Butler (2003), historicizando o corpo e o sexo, avança para pensar que a "natureza biológica" de homens e de mulheres oferece um campo limitado de problematizações para se pensar as práticas sociais humanas. Assim, afirma que em nossa sociedade se estabelece uma "ordem compulsória" que fixa o sexo biológico fora do campo social (portanto, fixa-o nas diferenças biológicas), exigindo uma comunicação total entre um sexo, um gênero e um desejo, que são marcados obrigatoriamente como heterossexuais. O conceito trazido por Butler (2003) desestabiliza a matriz heterossexual. Esta talvez seja a grande questão contra a qual se colocam os grupos religiosos: a não aceitação do fato de não haver uma coerência completa entre o sexo, a identidade de gênero e o desejo; e de haver pessoas que estão apresentando esse fato como forma de desnaturalizar o padrão heteronormativo.

No que se refere à diversidade sexual, o que temos defendido não é o fim da família nuclear, heteronormativa, mas a ampliação do conceito de família e a possibilidade de que os seres humanos construam os seus afetos sem as amarras do Estado. Observamos, nas matérias veiculadas em torno dessa discussão, que esse setor da sociedade entende a ideologia de gênero como a que determina a ausência do sexo desde o nascimento até sua decisão sobre por qual deles "optar": masculino ou feminino. Equivocam-se ao dizer que querem definir (ideologicamente, entendida como doutrinação) os comportamentos sexuais, pelos seguintes argumentos. Primeiro, porque a orientação sexual não é algo sobre o qual se possa fazer uma "opção" $e_{\text {, }}$ portanto, sobre o qual o/a professor/a possa interferir. A sexualidade é um fenômeno multifacetado que envolve as dimensões culturais, sociais, históricas, políticas, psicológicas e também as dimensões biológicas. Nesse sentido, a sexualidade não deve ser compreendida como simples questão de genética, de instintos ou de impulsos hormonais. Segundo, porque os/as professores/as têm realizado ações no sentido de garantir o respeito à sexualidade constituída por esses sujeitos; não a "troca de gênero" de meninos e meninas. A compreensão de que é o viés biológico que define a orientação sexual das pessoas num jogo binário, ou seja, nasceu com pênis será menino com todas as marcações culturais construídas para essa identidade, acaba forçando o enquadramento das pessoas a um padrão heteronormativo, mesmo aquelas que se orientam para um modo de sexualidade diferente desse padrão largamente legitimado socialmente.

Mesmo com a escola há anos trabalhando para o fortalecimento de um padrão heteronormativo, isso não garantiu que nossos meninos e meninas constituíssem sua sexualidade absolutamente dentro desse padrão. Ao contrário, a heteronormatividade 
tem produzido o sofrimento de meninos e meninas, mulheres e homens que não se enquadram nesse padrão. Os pressupostos de gênero e da diversidade sexual questionam o direito ao exercício de liberdade dos afetos, da sexualidade e do próprio corpo, ou seja, um direito humano.

Diferente do que vem sendo postulado pelos religiosos de plantão, o gênero não afirma que os seres humanos são naturalmente iguais, mas que não devem ser socialmente desiguais. É justamente $O$ inverso. $O$ conceito de gênero se apresenta paradenunciar que somos diferentes ${ }^{12}$, não apenas do ponto de vista biológico, mas, fundamentalmente, pelas construções socioculturais nas quais estamos envolvidos em nossas interações. Somos diferentes, sim, mas diferença não deve ser contraposta a desigualdade e sim a homogeneização. Igualdade deve ser oposta a desigualdade. Nesse sentido, apesar de diferentes, não podemos transformar essas diferenças em desigualdades e impedir as pessoas de acessarem direitos sociais que todo ser humano tem, independentemente de sua condição social ou orientação sexual.

Os direitos sociais, as políticas públicas e as ações críticas de diversos setores em relação às naturalizações no campo pedagógico, conquistados nos últimos anos, foram fruto justamente de muita luta de diversos atores sociais contra uma ideologia que pretendia "encaixar" as diferenças, impedindo que as pessoas que não se enquadrassem pudessem viver suas vidas como um direito social.

\section{O "ESCOLA SEM PARTIDO" "ESCOLA LIVRE": UMA "AÇÃO PACOTE" CONTRA AS DIFERENÇAS E O PENSAMENTO CRÍTICO NAS ESCOLAS}

É no contexto de ataques aos direitos humanos e, mais recentemente, à democracia brasileira, por meio da interrupção de um governo eleito, que situamos o projeto "Escola sem partido"13, denominado de "Escola Livre" no Estado do Espírito Santo. Em nível nacional, temos um conjunto de projetos de lei que visam constituir o "Escola sem partido". Na Câmara dos Deputados foram propostos dois projetos de lei: o PL no 867/2015, de 23 de março de 2015, que propõe incluir entre as Diretrizes e Bases da Educação Nacional, o "Programa Escola sem partido"; e o PL n 1. 411/2015, de 6 de maio de 2015, que tipifica o crime de assédio ideológico e dá outras providências (BRASIL, 2015). O Projeto de Lei do Senado (PLS) no 193/2016, de autoria do senador capixaba Magno Malta (PR/ES), que sugere incluir, entre as Diretrizes e Bases da Educação Nacional, o "Programa Escola sem partido", teve maior repercussão. Esse projeto propõe vedar "[...] a prática de doutrinação política e ideológica bem como a veiculação de conteúdos ou a realização de atividades que possam estar em conflito com as convicções religiosas ou morais dos pais ou responsáveis pelos estudantes" (BRASIL,2016). O projeto também é justificado com base no argumento da vulnerabilidade do educando e do direito dos pais/mães de oferecerem a seus filhos/as uma educação moral em conformidade com suas próprias convicções, o que reforça a pretensa crença desses atores na possibilidade de existência de uma educação neutra e de neutralidade do conhecimento. No entanto, o projeto em questão nada mais faz do que delimitar o que é considerado ideológico, logicamente, a partir de um único ponto 
de vista. Desconsideram o fato de que todo conhecimento é ideológico, seja para manter, seja para transformar ideias e ações (BRASIL, 2016).

O projeto "Escola sem partido" que, em nível nacional, diz estar garantindo os valores morais da família, representa um retrocesso, na medida em que dissemina concepções e práticas preconceituosas, discriminatórias e excludentes, o que as políticas públicas nacionais e práticas pedagógicas já vinham buscando superar nos últimos dez a quinze anos. Representa um retrocesso, quando retoma a perspectiva de que os/as estudantes precisam ser tutelados, privando-os da possibilidade de construção de uma consciência mais crítica quando a liberdade de ensino e aprendizagem está presente. $O$ projeto pressupõe estudantes incapazes de construir suas próprias reflexões, ideias e posições quanto às questões da vida. Fundamentalmente, esse projeto "[...] transforma o ato educativo em uma mera reprodução e expressão do poder vigente, rotulando toda abordagem crítica como subversiva à ordem social" (CARTA CAPITAL, 2016). Não é à toa que esses projetos passaram a ser denominados pelo professorado de "leis da mordaça"14.

A primeira tentativa da Comissão de Educação, Cultura e Esporte (CE) do Senado Federal de debater o PLS no 193/2016, ao propor a inclusão do programa "Escola sem partido" na Lei de Diretrizes e Bases da Educação Nacional (Lei no 9. 394/96), não foi bem-sucedida, pois a audiência pública foi interrompida devido a um protesto de estudantes e professores/as que se posicionam contrários à proposta. Sentindo-se hostilizado por ter sido chamado de golpista ${ }^{15}$, o relator do projeto, Cristovam Buarque (PPS-DF), suspendeu a sessão. No entanto, dias depois, a Comissão aprovou um requerimento da senadora Fátima Bezerra (PT-RN), para que se procedesse à retomada do debate. Assim, no dia 16-11-2016, a Comissão de Educação, Cultura e Esporte do Senado Federal voltou a debater o PLS no 193/2016 em audiência pública. A página do Senado ${ }^{16}$ traz a informação de que alguns defensores da proposta iniciaram um tumulto durante a sessão da Comissão e foram hostilizados. Lamentável também, nesse episódio, a ausência de Miguel Nagib no debate, coordenador do movimento "Escola sem Partido" (BRASIL, 2016).

Importante destacar que, nessa mesma sessão, a subprocuradora-geral da República, Deborah Duprat, afirmou que projetos inspirados no programa "Escola sem partido" atentam contra a Constituição Federal de 1988, em seu art. 205, e contra a Lei de Diretrizes e Bases da Educação Nacional (LDBEN no 9.394/96), em seus arts. $2^{\circ}$ e $3^{\circ}$, pois o projeto fere a liberdade de cátedra, o princípio da gestão democrática da escola e a autonomia administrativa e pedagógica dos sistemas de ensino. Além disso, esse programa estaria impondo "[...] o poder absoluto da família sobre as crianças, adolescentes e jovens, proibindo seu acesso a uma educação democrática, laica, inclusiva e emancipatória que se constitui em ambientes de convivência educacional de livre debate em torno de ideias e concepções" (CARTA CAPITAL, 2016). Nesse sentido, o 
PLS no 193/16 estaria afrontando o direito de aprendizagem como resultado de uma política de responsabilidade entre o Estado e a família, com a colaboração da sociedade, como exposto na LBDEN no 9.394/96. Na página de acompanhamento de Projetos do Senado, o PLS no 193/16 encontra-se em tramitação na Comissão de Educação, Cultura e Esporte, desde 3 de junho de 2016, com o relator, o senador Cristovam Buarque, até o fechamento deste artigo.

$\mathrm{Na}$ linha do que ocorreu em nível federal, em diversas unidades federativas foram disparados projetos similares, quando não idênticos, demonstrando ser essa uma ação coordenada, um pacote nacionalmente interposto. No Espírito Santo, o projeto "Escola sem Partido" ganhou novo nome, apesar de ser idêntico ao que foi proposto na Assembleia Legislativa de Alagoas, onde já havia sido apresentado pelo deputado Esmael de Almeida, em 2014. Chamado desta vez de "Escola Livre", o projeto que previa a instituição do programa "Escola Livre" nas escolas públicas do Estado foi apresentado pelo Deputado Hudson Leal (PTN/ES) na Assembleia Legislativa do Espírito Santo (Ales) em meados de maio de 2016, com os mesmos propósitos de eliminação da política como dimensão de debate e de formação do pensamento livre.

No dia 25-5-16, diversos setores do movimento sindical, social e acadêmico do Estado, e também em nível nacional, produziram notas de repúdio ${ }^{17}$ a esse projeto, protocolizaram na Ales e, inclusive, houve uma tentativa de alguns representantes de conversar com o propositor do projeto, o deputado Hudson Leal (PTN/ES). No entanto, o diálogo não foi possível, talvez porque o projeto, como em nível nacional, fazia parte dos instrumentos de disputa usados para respaldar os retrocessos em relação aos direitos humanos que se efetivavam com o golpe jurídico, parlamentar e midiático efetivado com o impeachment de Dilma Vana Roussef (2015-2016). O projeto fazia parte de uma ação-pacote orquestrada nacionalmente. Finalmente, por ter sido considerado inconstitucional pela Procuradoria da Ales, o projeto foi arquivado quando ainda se encontrava na Comissão de Educação.

Finalmente, é preciso dizer que esse conjunto de projetos de leis apresentados em nível nacional retoma os mecanismos utilizados no período da ditadura produzida pelo Golpe de 1964. Também, naquele período, foram criados mecanismos que impunham determinados conteúdos e metodologias de ensino que se colocavam em conformidade com a ideologia do golpe e que estabeleceram censuras a alguns conteúdos e autores sob a alegação de doutrinação ideológica. Esses mecanismos levaram à perseguição, repressão e até a tortura educadores que se colocavam contra o golpe e suas ideologias. A serem aprovados esses projetos, corremos o risco de "repetir" a História. Nesse sentido, é sempre muito bom lembrar o que Paulo Freire (1996) nos alerta:

Desse ponto de vista, que é reacionário, o espaço pedagógico, neutro por excelência, é aquele em que se treinam os alunos para práticas apolíticas, como se a maneira humana de estar no mundo fosse ou pudesse ser uma maneira neutra. Minha presença de professor, que não pode passar despercebida dos alunos na classe e na escola, é uma presença em si política. Enquanto presença não posso ser uma omissão, mas um sujeito de opções. Devo revelar aos alunos a minha capacidade de analisar, de comparar, de 
SILVA, E.M.; ALVARENGA, E.; AMORIM, F.L.A.; FERREIRA, E.B.

avaliar, de decidir, de optar, de romper. Minha capacidade de fazer justiça, de não falhar à verdade. Ético, por isso mesmo, tem que ser o meu testemunho (FREIRE, 1996, p. 38).

Assim, considerando o que Freire (1996) afirma, os/as professores/as precisam estar atentos/as à esperteza da classe dominante quando insinuam a neutralidade da educação.

\section{CONSIDERAÇÕES FINAIS}

Além do confronto legislativo apresentado, a partir do Golpe jurídico, parlamentar e midiático produzido contra o governo da Presidenta Dilma Vana Rousseff (2015-2016), os setores conservadores e dominantes no momento passaram a interferir diretamente sobre a condução das diversas políticas que vinham sendo implementadas pelos Ministérios, Secretarias e Coordenações do governo que sofreu o impeachment. Pudemos assistir, não sem luta, o esfacelamento da Secretaria Especial de Políticas para Mulheres, que tinha caráter de Ministério, mas retomou para uma secretaria sem força e sem projetos expressivos, bem como das Secretarias Secadi e Seppir. Foram esvaziadas diversas iniciativas e políticas que afirmavam uma educação para a igualdade de gênero e para o respeito e a valorização das diferenças.

Enfrentando esses ataques, vimos emergir em todo o país inúmeras manifestações de repúdio a esses movimentos reacionários. Além das manifestações já citadas, podemos ainda indicar, em se tratando de dispositivos legais, a Resolução n 12 do Conselho Nacional de Combate à Discriminação e Promoções dos Direitos de Lésbicas, Gays, Travestis e Transexuais (CNCD/LGBT, 2015) e a Portaria nº 916 do Ministério da Educação (MEC, 2015). Também vimos movimentos de professores/as reafirmando a responsabilidade social e científica dos processos educativos na luta contra toda forma de discriminação.

No âmbito educacional, o reconhecimento desse processo tem se situado como um campo fértil para reflexões e debates a respeito tanto da temática de gênero e diversidade sexual quanto da escola crítica e democrática. Vimos, em especial pelo "movimento das ocupaçóes" ocorrido no ano de 2016, que a vida na escola oferece diversos repertórios, por meio de suas experiências, identidades e culturas próprias. Com isso, torna-se cada vez mais evidente a importância de afirmar o processo de democratização das políticas educacionais e com a participação significativa dos movimentos sociais na produção de políticas públicas de educação voltadas para o gênero e para a diversidade sexual e educação em geral.

As reflexões aqui apresentadas abordam demandas desafiadoras à educação, logo, referentes aos sujeitos da escola, em um momento delicado da política brasileira. $\mathrm{O}$ debate acerca das políticas educacionais em curso está marcado por disputas emblemáticas no campo das ações afirmativas, especificamente no que diz respeito às questões de gênero e sexualidade. De um lado, o conservadorismo de parte dos legisladores e, de outro, as lutas em prol de políticas específicas para as ações afirmativas versus as lutas por espaços e tempos democráticos e plurais.

A inclusão da temática, por exemplo, da homossexualidade como um direito é marcada por disputas e resistências não só na produção das políticas públicas, mas também nos cotidianos escolares. É recorrente o discurso proposto de uma identidade 
rotulada. Nesses processos, as pessoas homossexuais são tratadas como se fossem iguais e vivessem suas sexualidades da mesma forma. Essa identificação coletiva da homossexualidade, ainda excluída na escola, não conseguiu garantir o seu direito de ser diferente, nem o reconhecimento nas políticas educacionais devido à construção heteronormativa da sociedade, atravessada por fatores religiosos e conservadores.

As possibilidades de consolidar conceitos, como gênero, diversidade sexual e diferença, na definição de políticas públicas para a educação e, logo, desestruturar a produção heteronormativa vêm, apesar dos percalços e desafios, fortalecendo-se com o alargamento significativo dos direitos sociais e humanos, com destaque à atuação e lutas dos movimentos sociais (feministas e LGBT) ${ }^{18}$. Porém, com o avanço das forças religiosas e conservadoras que ocupam o Poder Legislativo brasileiro, esse processo torna-se um dos desafios mais difíceis na agenda educacional e política do país.

Sobre o projeto "Escola sem partido" e a denominada "ideologia de gênero", vale sempre ressaltar que a escola e seus agentes ${ }^{19}$, quando comprometidos com a formação humana em sua omnilateralidade, têm grande importância no sentido de fazer os enfrentamentos necessários frente à desumanização, à coisificação do humano e ao pensamento acrítico, a-histórico. No entanto, enfrentamento não significa inculcação reprodutivista. A esse respeito vale relembrar o saudoso professor Florestan Fernandes (1966, p. 71), quando diz que "[...] não há dúvida de que a educação modela o homem. Mas é esse que determina, socialmente, a extensão das funções construtivas da educação em sua vida". Ademais, afirma que, se o/a cidadão/ã é compreendido como o agente histórico para a transformação da sociedade pela possibilidade de ser preparado com técnicas democráticas de organização do poder, é o/a professor/a o/a agente de formação desse/a cidadão/ã. Assim, ao/a professor/a cabe a tarefa de pensar e agir politicamente a partir das condições em que vivem seus estudantes: dos direitos que lhes cabem e dos que ainda carecem ser conquistados para uma vida cidadã plena.

Este artigo tem como objetivo compreender as ações políticas atuais em torno das discussões sobre doutrinação, gênero e diversidade sexual, em especial as tocantes às propostas denominadas "ideologia de gênero" e "Escola sem partido", bem como as tensões e as implicações desse debate para a compreensão do papel da escola e dos/as professores/as frente à formação humana. Para atender aos objetivos, utiliza a pesquisa bibliográfica. Nesse percurso, problematiza sobre as intencionalidades político-religiosas que recaem sobre essas propostas, compreendendo-as como duas ações articuladas. Conclui que, atualmente, o Brasil passa por um processo de contenção aos avanços nas políticas e ações sociais conquistados nos últimos 15 anos e, simultaneamente, por um movimento de resistências que perpassa, necessariamente, pelos processos educativos e pela ação de professores/as. 
THE "GENDER IDEOLOGY" AND THE "SCHOOL WITHOUT PARTY": FACES OF THE SAME COIN IN CONSERVATIVE POLITICAL ACTIONS IN BRAZIL AND IN THE ESPÍRITO SANTO

ABSTRACT: This article aims to understand the current political actions around the discussions about indoctrination, gender and sexual diversity, particularly those related to the proposals called "gender ideology" and "School without party", as well as the tensions and the implications of this debate for the understanding of the role of school and teachers in the face of the human formation. To meet the objectives, a bibliographical research was done. In this way, discusses about the political-religious intentions that fall on these proposals, understanding them as two articulated actions. Concludes that, currently, Brazil is going through a process of containment to advances in political and social actions achieved in recent 15 years and, simultaneously, a movement of resistance that pass through, necessarily, educational processes and the teacher's actions.

KEYWORDS: Public Policy. Social actors. Gender ideology. School without party.

\section{LA "IDEOLOGÍA DE GÉNERO" Y LA "ESCUELA SIN PARTIDO": CARAS DE UNA MISMA MONEDA EN LA ACCIÓN POLÍTICA CONSERVADORA EN BRASIL Y EN EL ESPÍRITO SANTO}

RESUMEN: Este artículo tiene como objetivo comprender las acciones políticas actuales en torno a las discusiones sobre adoctrinamiento, género y diversidad sexual, en especial las tocantes a las propuestas denominadas "ideología de género" y "Escuela sin partido", así como las tensiones y las implicaciones de ese debate para la comprensión del papel de la escuela y de los profesores/as frente a la formación humana. Para atender a los objetivos propuestos utiliza la investigación bibliográfica. En ese camino, problematiza sobre las intencionalidades político-religiosas que recaen sobre esas propuestas, comprendiéndolas como dos acciones articuladas. Concluye que, actualmente, el Brasil pasa por un proceso de contención a los avances en las políticas y acciones sociales conquistadas en los últimos 15 años $y$, simultáneamente, por un movimiento de resistencias que atraviesa necesariamente por los procesos educativos y por la acción de profesores/as.

PALABRAS CLAVE: Políticas Públicas. Actores sociales. Ideología de género. Escuela sin partido.

\section{NOTAS}

1) No Espírito Santo, esse projeto ingressa na Assembleia Legislativa como o nome de "Escola livre".

2) Vide a criação das seguintes secretarias: Secretaria Especial de Políticas para as Mulheres (SPM); Secretaria de Educação Continuada, Alfabetização, Diversidade e Inclusão (Secadi); Secretaria de Políticas de Promoção da Igualdade Racial (Seppir).

3) Essa Igreja se localiza no Rio de Janeiro. 
4) O artigo da filósofa Miclela Marzano foi traduzido por Moisés Sbardelotto e está disponível em: <http://midiareligiaopolitica.blogspot.com.br/2015/06/grupos-religiosos-conservadoresreagem.html>. Acesso em: 10 jul. 2017.

5) A carta com a Declaração de Dom Luiz Mancilha Vilela está disponível em: < http://aves.org.br/wp-

content/uploads/2015/06/DeclaracaodeDomLuizMancilhaVilelasobreaideologiadegenero_201506 22064409.pdf >. Acesso em: 25 jul. 2017.

6) Ver matéria intitulada Orientação sexual e homofobia em debate no jornal "A Gazeta", do dia 18 de setembro de 2015.

7) Ver matéria de Julia Grillo, Fórum LGBT do ES repudia carta de arcebispo sobre "ideologia de gênero". Disponível em:< http://g1.globo.com/espirito-santo/noticia/2015/06/forum-lgbt-do-esrepudia-carta-e-arcebispo-sobre-ideologia-de-genero.html>. Acesso em: 25 jul. 2017.

8) Além da luta empreendida pelo Comev na defesa da manutenção das questões de gênero e diversidade no Plano Municipal de Educação no ano de 2015, destaca-se a sua persistência na revisão do Plano Municipal nas conferências de Educação realizadas durante o mês de agosto de 2017 para que as questões de gênero e diversidade configurassem no Plano Municipal. Ademais, destacamos o acompanhamento realizado por esse Conselho nas diversas situações ocorridas em conflitos que envolveram algumas escolas mais diretamente e grupos de pais e pastores evangélicos do município. Sobre esses conflitos, ver matéria disponível em: <http://g1.globo.com/espirito-santo/noticia/escola-de-vitoria-sofre-atos-de-vandalismo-ecoordenador-relata-ameacas-por-conta-de-abordagem-sobre-diversidade-sexual.ghtml>. Acesso em: 14 jul. 2017.

9) Os vereadores da bancada religiosa da Câmara Municipal de Vitória, nesses diálogos realizados, chegaram a propor que os termos gênero e diversidade sexual voltassem ao texto do Plano Municipal de Educação, desde que concordassem em diminuir o percentual estipulado para a educação no Orçamento Municipal de $35 \%$ para $25 \%$, ou seja, manter o percentual mínimo que a Constituição Federal de 1988 garante, o que já havia sido superado na Capital.

10) Em princípio, acreditávamos que a exclusão da discussão étnico-racial se devia ao fato de o tema compor com gênero e diversidade um mesmo parágrafo, mas com a aprovação da MP 746/16 do Ensino Médio, que não menciona essa temática, percebemos que as questões étnicoraciais também estão sendo objeto desse ataque conservador, apesar da Lei no 10.639/2003. Ressaltamos que esses trâmites foram acompanhados diretamente por uma das autoras deste artigo.

11) Estamos ainda em processo de levantamento desses dados.

12) Quando falamos em diferença, temos que tomar certo cuidado para não cairmos num relativismo proposto pela teoria da diferença, levando-a ao limite do subjetivismo. Nessa perspectiva, todos somos, o tempo todo, diferentes e em nada nos igualamos. Partimos do pressuposto de que a subjetividade, constituída na e pela diferença, só existe na relação dialética com a coletividade e com o social. Ao nos colocarmos em relação com outras pessoas e outras identidades, estabelecemos proximidades que podem "furar fronteiras" dessa fragmentação, de forma que também nos encontramos pelas nossas diferenças e podemos, por elas, estabelecer 
relação, ainda que conflituosa, de articulação social. Ademais, ao falar em diferença, não podemos entendê-la como forma de subsumir as desigualdades a que tanto o patriarcado, o racismo e o capitalismo submetem as pessoas cotidianamente.

13) Além do PLS n 193/2016 que foi apresentado no Senado, encontram-se na Câmara Federal o PL no 1.411/2015, de autoria do deputado Rogério Marinho (PSDB/RN), que tipifica o crime de assédio ideológico e dá outras providências; o PL n 867/15, que apresenta o programa "Escola sem partido" na Câmara de Deputados, de autoria do deputado Izalci Lucas Ferreira (PSDB/DF), e o projeto sobre valores familiares nas escolas (PL n 7.180/14), de autoria Erivelton Santana (PSC/BA). Disponível em: <http://www.camara.gov.br/ proposicoesWeb/fichadetramitacao?> . Acesso em: 28 dez. 2016.

14) Outra proposta que parece confirmar serem esses conjuntos de projetos "Leis da mordaça" é o PL no 1.411/15, que tramita na Câmara e foi apresentado pelo deputado Rogério Marinho (PSDBRN). Esse projeto prevê a possibilidade de detenção de três meses a um ano para o/a professor/a que expuser aluno/a a assédio ideológico (entendido como qualquer pensamento crítico que seja contrário ao pensamento da ordem).

15) Termo que passou a ser referência àqueles/as que votaram a favor do impeachment da Presidenta Dilma Vana Rousseff.

16) Informação obtida no site do Senado, na página Notícias do Senado, por Marcela Diniz. Disponível em: <https://www12.senado.leg.br/noticias/audios/2016/10/comissao-vai-retomardebate-sobre-programa-escola-sem-partido>. Acesso em: 28 dez. 2016.

17) Foram produzidas duas notas, pelo menos, uma intitulada Nota Pública por uma educação democrática e a outra Nota de Repúdio contra projeto de lei a ser apresentado pelo Deputado Estadual Hudson Leal (PTN/ES). Assinaram essas notas: Campanha Nacional pelo Direito à Educação e seus comitês Mineiro e Capixaba, Comitê Estadual de Educação Quilombola do ES, Conselho Popular de Vitória (CPV), União Nacional dos Conselhos Municipais de Educação (Uncme), Movimento interfóruns de Educação Infantil (Mieib), Sindicato dos Trabalhadores/as em Educação Pública do Espírito Santo (Sindiupes), Sindicato Nacional de Servidores Federais da Educação Básica - Espírito SantoS (Sinasefe), Laboratórios e núcleos de pesquisa da Ufes (Lagebes, Nedi, Nepe, Neesp, Laefa, Lahis e Práxis), União Nacional dos Estudantes (Une), União Brasileira dos Estudantes Secundaristas (Ubes), Movimento Sem Terra (MST), Associação Brasileira de Lésbicas, Gays, Bissexuais, Travestis e Transexuais (ABGLT), Seção Sindical do Sindicato Nacional dos Docentes no Espírito Santo (Adufes), Associação Nacional de História (Anpuh), Central Única dos Trabalhadores (Cut), Fórum de Mulheres do Espírito Santo, Associação Nacional de Pesquisadores em Financiamento da Educação (Fineduca), Movimento de Mulheres Camponesas, dentre outros.

18) Sigla que designa "Lésbicas, Gays, Bissexuais, Travestis, Transexuais e Transgêneros", grupo que compõe o movimento civil por direitos sociais igualitários.

19) No processo social e educacional de tensões, de disputas e de escolhas, a figura do/a professor/a e o trabalho que realiza são essenciais, na medida em que, mesmo que orientado por planos, programas etc., é a pessoa que está na ponta da ação educacional, fazendo os enfrentamentos cotidianos com seus alunos/as, com seus pares e com "sua" comunidade em relação aos diversos desafios que a realidade social lhe apresenta.

\section{REFERÊNCIAS}


A "ideologia de gênero" e a "escola sem partido"...

BOURDIEU, P. A economia das trocas simbólicas. São Paulo: Perspectiva, 2005.

BRASIL. Câmara dos Deputados. Projeto de Lei no867, de 23 de março de 2015, inclui entre as Diretrizes e Bases da Educação Nacional, o "Programa Escola sem partido". Distrito Federal, 2015.

Câmara dos Deputados. Projeto de Lei no 1. 411, de 6 de maio de 2016, tipifica o crime de assédio ideológico e dá outras providências. Distrito Federal, 2015.

Senado Federal. Projeto de Lei no193, de 4 de maio de 2016, inclui entre as Diretrizes e Bases da Educação Nacional, o "Programa Escola sem partido". Distrito Federal, 2016.

BUTLER, J. Problemas de gênero: feminismo e subversão da identidade. Rio de Janeiro: Civilização Brasileira, 2003.

CARTA CAPITAL. Escola sem partido: estratégia golpista para calar a educação. Disponível em: $<$ https://www.cartacapital.com.br/educacao/escola-sem-partido-estrategia-golpista-paracalar-a-educacao>. Acesso em: 14 jul. 2017.

CONSELHO NACIONAL DE COMBATE À DISCRIMINAÇÃO E PROMOÇÕES DOS DIREITOS DE LÉSBICAS, GAYS, TRAVESTIS E TRANSEXUAIS (CNCD/LGBT). Resolução no 12, de 15 de janeiro de 2015, estabelece parâmetros para a garantia de acesso e permanência de pessoas travestis e transexuais [...]. Brasília, 2015.

CONFEDERAÇÃO NACIONAL DOS BISPOS DO BRASIL (CNBB). Nota da CNBB sobre a inclusão da ideologia de gênero nos Planos de Educação. Disponível em: <http://www.cnbb.org.br/imprensa1/noticias/16732-cnbb-divulga-nota-sobre-a-inclusao-da-ideologia-de-genero-nos-planos-deeducacao >. Acesso em: 10 jul. 2015.

FARIA, N.; NOBRE, M. Gênero e desigualdade: o que é ser mulher? O que é ser homem? Subsídios para uma discussão das relações de gênero. Cadernos Sempreviva. São Paulo: Sempreviva Organização Feminista (SOF), 1997.

FERNANDES, F. Educação e sociedade no Brasil. São Paulo: Dominus/Edusp, 1966.

FREIRE, P. Pedagogia da autonomia: saberes necessários à prática educativa. (Coleção Leitura). São Paulo: Paz e Terra, 1996.

MALAFAIA, S. Eu sou um pastor que luto para praticar a palavra de Deus [...]. Entrevista concedida a Sânnie Rocha. Comunhão. Espírito Santo, p. 12-16, jul. 2015.

MARZANO, M. A cruzada contra o gênero, o fantasma que agita os católicos. Jornal La Repubblica. 22 jul. 2015. Disponível em: <http://midiareligiaopolitica.blogspot.com.br/2015/06/gruposreligiosos-conservadores-reagem.html>. Acesso em: 10 jul. 2015.

MINISTÉRIO DA EDUCAÇÃO (MEC). Portaria no 916, de 9 de setembro de 2015, institui Comitê de Gênero, de caráter consultivo, no âmbito do Ministério da Educação. Brasília, 2015.

REIS, T. A "ideologia de gênero", a equidade e os planos de educação. Disponível em: $<$ http://www.anped.org.br/news/a-ideologia-de-genero-a-equidade-e-os-planos-de-educacao>. 
SILVA, E.M.; ALVARENGA, E.; AMORIM, F.L.A.; FERREIRA, E.B.

Acesso em: 10 jul. 2017.

RODRIGUES, A.; DALLAPICULA, C.; BARRETO, M. P. S. C. Expressão de sujeitos de poder nas marcas culturais e nas políticas da vida. In: BARRETO, M. A. S. C.; RODRIGUES, A. (Org.). Currículos, gêneros e sexualidades. experiências misturadas e compartilhadas. Vitória, Espírito Santo: Edufes, 2012.

SCOTT, J. Gênero: uma categoria útil de análise histórica. Educação e Realidade, Porto Alegre, v. 20, n. 2, p. 9-17. jul./dez. 1995.

SERRA. Câmara Municipal de Vereadores. Projeto de Lei no 124, de 26 de junho de 2015, proíbe, no âmbito do município da Serra/ES, a promoção da diversidade de gênero nas escolas públicas e particulares. Serra, 2015.

ERINeusa Maria da SILVA: Professora na Universidade Federal do Espírito Santo (UFES). Doutoranda em Educação no PPGE/UFES. Membro e pesquisadora do NEPE/CE/UFES e do PRAXIS/UFES.

E-mail: erineusa@uol.com.br

Elda Alvarenga: Professora da Faculdade Estácio de Vila Velha. Doutoranda em Educação no PPGE/UFES. Membro e pesquisadora do NUCAPHE/UFES.

E-mail: eldaalvarenga@uol.com.br

FÁBio Luiz Alves de Amorim: Professor na Faculdade Estácio de Vitória. Doutorando em Educação no PPGE/UFES. Membro representante da ANFOPE.

E-mail: fabioamorim36@gmail.com

Eliza Bartolozzi Ferreira: Professora na Universidade Federal do Espírito Santo. Doutora em Educação. Coordenadora do PPGE/UFES. Coordenadora do NEPE/UFES.

E-mail: eliza.bartolozzi@gmail.com 